\title{
Morphological description and phylogenetic estimation of Favolus roseus (Polyporaceae): first documented records for the Indian mycobiota
}

\author{
Vijay Udhav Gore ${ }^{1}$, Manoj Emanuel Hembrom², Aniket Ghosh ${ }^{3}$, Vasant Pandit Mali ${ }^{4}$, \\ Arun Vincent $\mathrm{Kisku}^{5 *}$ \\ 1 Shiveshwar Junior College, Takli (Antur), Kannad, Aurangabad, Maharashtra, India •vijaygore777@gmail.com \ttps://orcid.org/0000-0002- \\ 4015-0535 \\ 2 Acharya Jagadish Chandra Bose Indian Botanic Garden, Botanical Survey of India, P.O. Botanic Garden, Howrah, India • manojhembrom@bsi. \\ gov.in (1) https://orcid.org/0000-0001-6710-8882 \\ 3 Department of Botany and Microbiology, H.N.B. Garhwal University, Srinagar, Garhwal, India • ghosh.aniket87@gmail.com (D https://orcid. \\ org/0000-0001-9905-118X \\ 4 Watumull Sadhubella Girls College, Thane, Maharashtra, India • vasant.mali@rediffmail.com @ https://orcid.org/0000-0003-3592-1937 \\ 5 St. Xavier’s College, Maharo, Dumka, Jharkhand, India • arunkisku@gmail.com @ https://orcid.org/0000-0001-9148-0270 \\ * Corresponding author
}

\begin{abstract}
During the course of macrofungal forays, we collected several wood-rotting fungi from three states in India: Bihar, Jharkhand, and Maharashtra. We identified some of these macrofungal collections as Favolus roseus Lloyd. A critical literature survey and taxonomic investigation established that this is the first report of $F$. roseus from India. We give a detailed morphological description, illustration, and molecular phylogeny of the species, along with taxonomic note and extended biogeographical distributional map.
\end{abstract}

\section{Keywords}

Distribution, new records, phylogenetic inference, species complex, taxonomy

Academic editor: Ajay Kumar Gautam | Received 17 March 2021 | Accepted 2 Jun 2021 | Published 30 August 2021

Citation: Gore VU, Hembrom ME, Ghosh A, Mali VP, Kisku AV (2021) Morphological description and phylogenetic estimation of Favolus roseus (Polyporaceae): first documented records for the Indian mycobiota. Check List 17 (4): 1171-1180. https://doi.org/10.15560/17.4.1171

\section{Introduction}

The generic epithet Favolus P. Beauv. was first used by Palisot de Beauvois (1805) for a single species, F. hirsutus P. Beauv., which was originally collected in Africa and had a characteristic honeycomb-like hymenophore. During the taxonomic history of Favolus (Corner 1984; Ryvarden 1991; Núñez and Ryvarden 1995, 2001; Ryvarden and Iturriaga 2004; Silveira and Wright 2005;
Drechsler-Santos et al. 2008), it had several times been considered to be synonym of Polyporus P. Micheli ex Adans. due to overlapping morphological attributes. One such remarkable taxon is Polyporus tenuiculus P. Beauv., which is morphologically highly variable; its gradual collection and characterization from North America, China, and Europe has lead to the realization that it is a species 
complex (Núñez and Ryvarden 1995, 2001). Using a molecular phylogenic approach, this complex has been demystified into three species, namely $F$. brasiliensis (Fr.) Fr., F. roseus Lloyd, and F. spatulatus (Jungh.) Lév. (Sotome et al. 2013). However, the validity of $F$. tenuiculus is questioned due to inaccessibility of its type specimen (Sotome et al. 2013). Sotome et al. (2013) revisited the taxonomic complexity of the genera Polyporus and Favolus and re-shuffled many species-level taxa based on morphology and molecular phylogeny. They defined Favolus as having laterally stipitate basidiomata, radially striate pileus, and non-crustose stipe surface macro-morphologically, while in sister genus Neofavolus Sotome \& T. Hatt., there is a micro-morphologically absence of any distinct cuticle. The monophyletic nature of the genus Favolus is now widely supported by multigene phylogenetic studies based on materials from several regions around the world (Zhao and Cui 2017; Xing et al. 2020; Palacio et al. 2021).

Within the genus Favolus, the relatively small basidiomata with a grayish-orange to yellowish-orange pileus surface and large radially elongated pores makes $F$. roseus distinct from other species (Sotome et. al. 2013). So far materials for taxonomic study have been reported from Sri Lanka, Malaysia, and Singapore in Asia (Sotome et. al. 2013) and Tanzania in Africa (Juma et al. 2016). Indian species of Favolus are mostly based on morphological characters (Bakshi 1971; Bilgrami et al. 1991; Roy and De 1996; Leelavathy and Ganesh 2000; Mohanan 2011; Sharma 2012) and many of them are lacking phylogenetic data for comparison with other counterparts. During our study of poroid wood-rotting macro-fungi from tropical India, we have collected many interesting specimens of Favolus from three states: Maharashtra (Deccan Plateau); Bihar (Terai region), and Jharkhand (Rajmahal Hills). Critical macro- and micromorphology characterization, coupled with combined nrITS and nrLSU-based phylogenetic studies (Fig. 1), revealed these specimens to be $F$. roseus, a species that has never been reported from India. Here, we report $F$. roseus for the first time from India and provide a detailed morphological description and a phylogenetic estimation using combined nrITS + nrLSU genes.

\section{Methods}

Representative survey sites included areas in the Indian states of Bihar, Jharkhand, and Maharashtra where collections of fruiting bodies/basidiomata were made by $\mathrm{MEH}, \mathrm{GV}$, and AVK during August to October from 2013 to 2019. Geographic coordinates were recorded using a Garmin e-trax30 hand-held GPS receiver. Fresh specimens were macromorphologically characterized, including nature of the host, in the field and their color was noted using the Methuen Handbook of Colour (Kornerup and Wanscher 1978) as a guide. The specimens were dried under hot air $\left(50-60{ }^{\circ} \mathrm{C}\right)$ using room heater. Dried specimens were separated into two parts for molecular and micromorphological characterization, and kept in brown paper packets sealed in an air-tight polybag to avoid moisture and insect attack. Thin sections were randomly cut from tubes, context, and pilear surfaces covering the margin to central and basal regions of the basidiocarps using sharp blades. A $10 \% \mathrm{KOH}$ solution was used to soften tissues, and lactophenol cotton blue and phloxine were used for staining. Melzer's reagent was chosen for testing the amyloidy of basidiospores and hyphae. Micromorphological observations, measurements, drawings and photography were done under an Olympus CX41 light microscope equipped with a 100× objective (oil immersion), drawing tube, and photographic attachments. All specimens were deposited at Central National Herbarium (CAL). The distributional map (Fig. 2) was produced in Arc GIS v. 10.5 (licensed to BSI, $\mathrm{CNH}$, Howrah).

DNA extraction, PCR amplification and sequencing. Genomic DNA was extracted from $100 \mathrm{mg}$ of dried basidiomes with the InstaGeneTM Matrix Genomic DNA isolation kit (Biorad, USA) following the manufacturer's instructions. The nrITS and nrLSU gene regions were amplified with primer pairs ITS-1F and ITS-4R (White et al. 1990) and LR0R and LR7 (Vilgalys and Hester 1990), respectively. PCR amplification was performed on a thermal cycler (Eppendorf, Germany) programmed for 2 min at $94{ }^{\circ} \mathrm{C}$, followed by 35 cycles of $45 \mathrm{sec}$ at $94{ }^{\circ} \mathrm{C}, 1 \mathrm{~min}$ at $55^{\circ} \mathrm{C}, 1 \mathrm{~min}$ at $72{ }^{\circ} \mathrm{C}$, and a final extension of $10 \mathrm{~min}$ at $72{ }^{\circ} \mathrm{C}$. The PCR products were purified using the QIAquick PCR Purification Kit (QIAGEN, Germany). Both strands of the PCR fragment were sequenced on the 3730xl DNA Analyzer (Applied Biosystems, USA) using the amplifying primers. The sequence quality was checked using Sequence Scanner Software v. 1 (Applied Biosystems). Sequence alignment and required editing of the obtained sequences were carried out using Geneious v. 5.1 (Drummond et al. 2010). All sequences newly generated in this study were submitted to GenBank. Accession numbers of species used in the phylogenetic analysis are listed in the Table 1.

Sequence alignment and phylogenetic analysis. The nrITS and nrLSU sequences of Favolus, Neofavolus, Polyporus, and outgroups were acquired from a Blast search (Altschul et al. 1997), GenBank (Clark et al. 2016), and relevant literature (Sotome et al. 2013; Papp and Dima 2017; Zhou and Cui 2017). The nrITS and nrLSU sequences were initially aligned with MAFFT v. 7 (Katoh et al. 2019) using default settings and manually edited with MEGA v. 7 (Kumar et al. 2016). Two single-locus datasets were concatenated into one multiloci dataset using BioEdit v. 7.0.9 (Hall 1999). The multilocus dataset was phylogenetically analyzed using the maximum likelihood (ML) method. A ML phylogenetic analysis was carried out using in raxmlGUI v. 2.0 (Edler et al. 2021) with the GTRGAMMA substitution model. A maximum likelihood bootstrap (MLB) analysis with 1,000 replicates was performed using sequences 


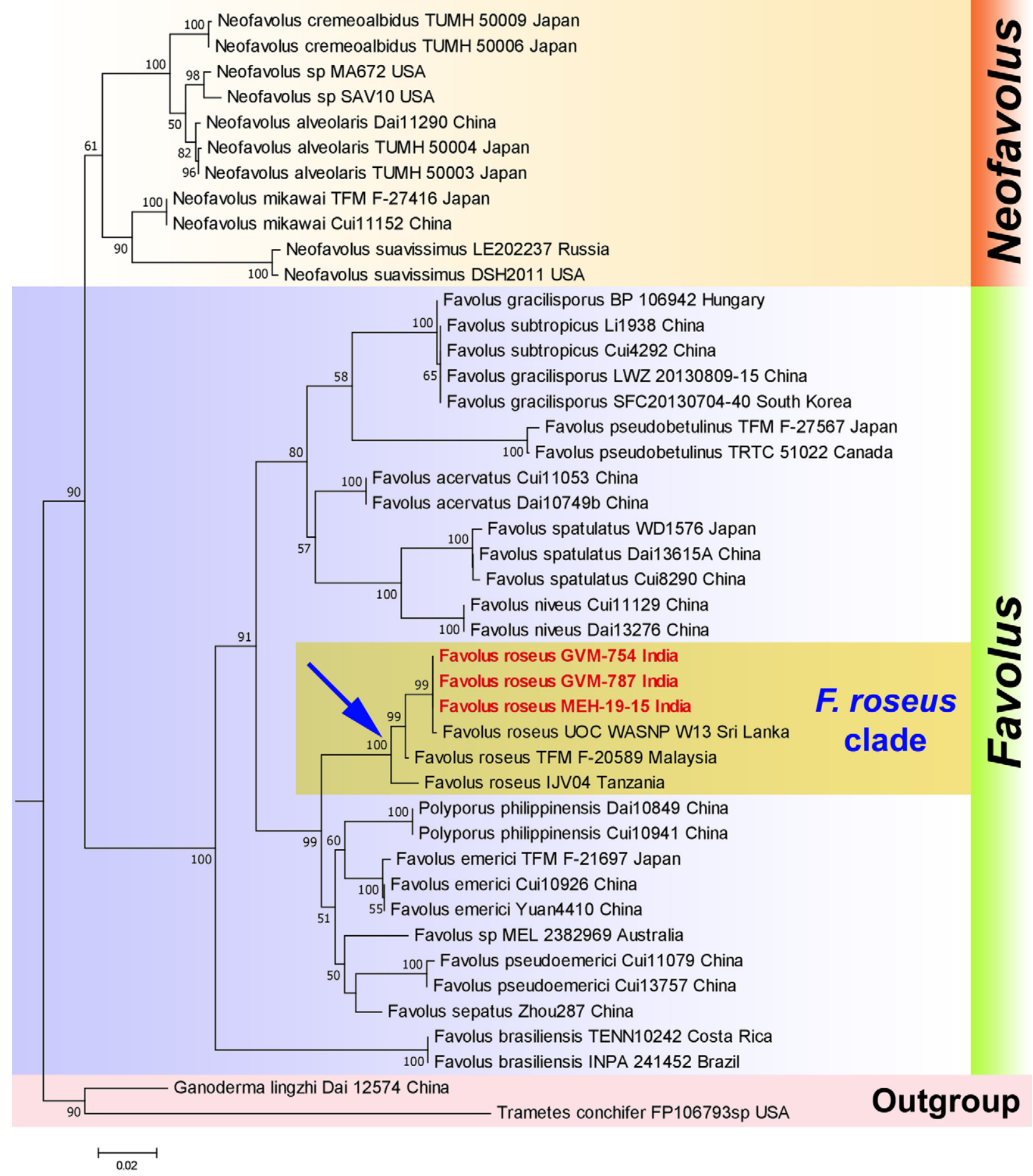

Figure 1. A maximum likelihood (ML) phylogram inferred from raxmIGUI v. 2.0 on a concatenated dataset of nrITS and nrLSU sequence data of Favolus and Neofavolus species. Bootstrap support values ( $\geq 50 \%)$ obtained from ML analysis are shown above or below the branches at nodes. Three collections of our Indian Favolus roseus species are shown in red and bold font in the phylogram.

of Ganoderma lingzhi Sheng H. Wu, Y. Cao \& Y.C. Dai and Trametes conchifer (Schwein.) Pilát as outgroups. MLB of $\geq 50 \%$ and above was considered significant support for clades.

\section{Results}

Favolus roseus Lloyd, Mycol. Writ. 7(Letter 67): 1157. (Lloyd 1922)

Figures 3, 4
Material examined. INDIA - Maharashtra • Marathwada, Aurangabad district, Taluka Kannad, Puranwadi; $20^{\circ} 22^{\prime} 02^{\prime \prime} \mathrm{N}, 075^{\circ} 11^{\prime} 47^{\prime \prime} \mathrm{E}$; alt. $718 \mathrm{~m}$; on logs of Mangifera indica L.; 17.VIII.2014; Gore Vijay (GVU/MVP26) - Marathwada, Aurangabad district, Taluka Kannad, Nevpur; $20^{\circ} 23^{\prime} 03^{\prime \prime} \mathrm{N}, 075^{\circ} 20^{\prime} 06^{\prime \prime} \mathrm{E}$; alt. $655 \mathrm{~m}$; on logs of M. indica; 12.IX.2014; Gore Vijay (GVU/MVP-113) • Marathwada, Aurangabad district, Taluka Kannad, Barkatpur; $20^{\circ} 22^{\prime} 30^{\prime \prime} \mathrm{N}, 075^{\circ} 23^{\prime} 29^{\prime \prime} \mathrm{E}$; alt. $640 \mathrm{~m}$; on living 


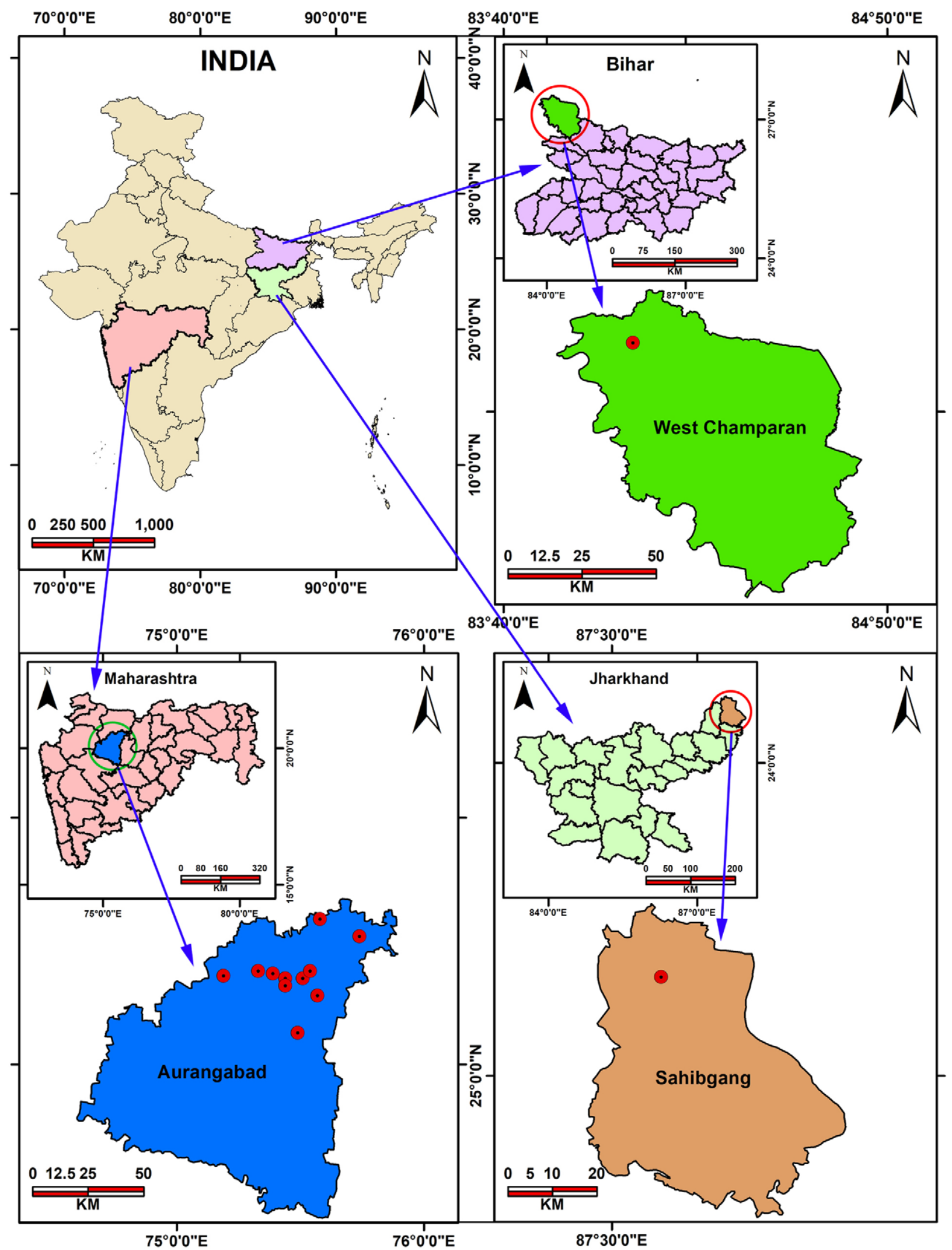

Figure 2. Distributional map of Favolus roseus in India.

tree of Zizyphus mauritiana Lam.; 29.VII.2016; Gore Vijay (GVU/MVP-209) • Marathwada, Aurangabad district, Taluka Kannad, Digoan; 20²1'03"N, 075²6'57"E; alt. $630 \mathrm{~m}$; on living Senna siamea (Lam.) H.S. Irwin \& Barneby; 08.VIII.2016; Gore Vijay (GVU/MVP-243) - Marathwada, Aurangabad district, Taluka Kannad,
Aadgoan; $20^{\circ} 19^{\prime} 30^{\prime \prime} \mathrm{N}, 075^{\circ} 26^{\prime} 41^{\prime \prime} \mathrm{E}$; alt. $650 \mathrm{~m}$; on the wood logs of $M$. indica; 08.X.2016; Gore Vijay (GVU/ MVP-512) - Marathwada, Aurangabad district, Taluka Phulambri, Pharshi phata; $20^{\circ} 08^{\prime} 16^{\prime \prime} \mathrm{N}, 075^{\circ} 29^{\prime} 40^{\prime \prime} \mathrm{E}$; alt. $616 \mathrm{~m}$; on the wood logs of $M$. indica; 04.X.2016; Gore Vijay (GVU/MVP-455) • Marathwada, Aurangabad 
Table 1. A list of species, voucher no., GenBank accession no. and reference of species used in this study.

\begin{tabular}{|c|c|c|c|c|}
\hline \multirow{2}{*}{ Species name } & \multirow{2}{*}{ Voucher no. } & \multicolumn{2}{|c|}{ GenBank accession no. } & \multirow[t]{2}{*}{ Reference } \\
\hline & & ITS & nrLSU & \\
\hline Favolus acervatus & Cui11053 & KU189774 & KU189805 & Zhou and Cui 2017 \\
\hline F. acervatus & Dai10749b & KX548953 & - & Zhou and Cui 2017 \\
\hline F. brasiliensis & INPA241452 & AB735977 & AB735953 & Zhou and Cui 2017 \\
\hline F. brasiliensis & TENN10242 & AB735976 & AB368097 & Zhou and Cui 2017 \\
\hline F. emerici & Cui10926 & KU189776 & KU189807 & Zhou and Cui 2017 \\
\hline F. emerici & Yuan 4410 & KX548954 & - & Zhou and Cui 2017 \\
\hline F.emerici & TFM F-21697 & AB735972 & AB735951 & Sotome et al. 2017 \\
\hline F. gracilisporus & BP 106942 & MF401551 & - & Papp and Dima 2017 \\
\hline F. gracilisporus & $\begin{array}{c}\text { LWZ } \\
\text { 20130809-15 }\end{array}$ & KM385429 & - & Papp and Dima 2017 \\
\hline F. gracilisporus & SFC20130704-40 & KY038472 & - & Papp and Dima 2017 \\
\hline F. niveus & Cui11129 & KX548955 & - & Zhou and Cui 2017 \\
\hline F. niveus & Dai13276 & KX548956 & - & Zhou and Cui 2017 \\
\hline F.philippinensis & Cui10941 & KX548976 & - & Zhou and Cui 2017 \\
\hline F. philippinensis & Dai10849 & KX548978 & - & Papp and Dima 2017 \\
\hline F. pseudobetulinus & TRTC 51022 & AB587629 & AB587620 & Zhou and Cui 2017 \\
\hline F.pseudobetulinus & TFM F-27567 & AB587644 & AB587639 & Zhou and Cui 2017 \\
\hline F.pseudoemerici & Cui11079 & KX548958 & - & Zhou and Cui 2017 \\
\hline F.pseudoemerici & Cui13757 & KX548959 & - & Zhou and Cui 2017 \\
\hline F. roseus & IJV04 & KM593876 & - & $\begin{array}{l}\text { Juma et al. 2016; } \\
\text { Papp and Dima } 2017\end{array}$ \\
\hline F. roseus & TFM F-20589 & AB735975 & AB368099 & Sotome et al. 2017 \\
\hline F. roseus & UOC WASNP W13 & KR049231 & - & Papp and Dima 2017 \\
\hline
\end{tabular}

district, Taluka Sillod, Ajanta; 20 31'14"N, 07544'47"E; alt. $583 \mathrm{~m}$; on living, main tree trunk of Ficus benghalensis L.; 16.VII.2016; Gore Vijay (GVU/MVP-204) • Marathwada, Aurangabad district, Taluka Sillod, Kalewadi; $20^{\circ} 21^{\prime} 28^{\prime \prime} \mathrm{N}, 075^{\circ} 30^{\prime} 40^{\prime \prime} \mathrm{E}$; alt. $623 \mathrm{~m}$; on living, main tree trunk of F. benghalensis; 04.VIII.2016; Gore Vijay (GVU/MVP-227) • Marathwada, Aurangabad district, Taluka Sillod, Kasod; $20^{\circ} 23^{\prime} 11^{\prime \prime} \mathrm{N}, 075^{\circ} 32^{\prime} 28^{\prime \prime} \mathrm{E}$; alt 633 m; on log of Albizia lebbeck (L.) Benth.; 27.VIII.2016, Gore Vijay (GVU/MVP-289) • Marathwada, Aurangabad district, Taluka Sillod, Palshi; $20^{\circ} 16^{\prime} 56^{\prime \prime} \mathrm{N}, 075^{\circ} 34^{\prime} 15^{\prime \prime} \mathrm{E}$; alt. 629 m; on log Ficus racemosa L.; 31.X.2019; Gore Vijay (GVM-754) • ibid.; Taluka Soygoan, Hadas Kankarada; $20^{\circ} 35^{\prime} 45^{\prime \prime} \mathrm{N}, 075^{\circ} 35^{\prime} 03^{\prime \prime} \mathrm{E}$; alt. $333 \mathrm{~m}$; on $\log$ of Vachellia nilotica (L.) P.J.H. Hurter \& Mabb. 09.XI.2019; Gore Vijay (GVM-787) - Jharkhand - Sahibganj district, Mandro Block, on the forest way to Chaldhi from Chota Solbandha; 25 $12^{\prime} 40^{\prime \prime} \mathrm{N}, 087^{\circ} 36^{\prime} 30^{\prime \prime} \mathrm{E}$; alt. 229 m; on dead branches of Morus alba L.; 18.VIII.2013; ME Hembrom (MEH-13-008) - Bihar • West Champaran district, Valmiki National Park; 27²6'22.7"N, 08356'39"E; alt. $137 \mathrm{~m}$; on dead branches of Shorea robusta Gaertn. 11.X.2019; ME Hembrom (MEH-19-15).

Identification. Basidiomata annual, solitary to caespitose or in groups, leathery when fresh, brittle when dried, substipitate to almost pileate with tapered base, easily separable from host wood. Pileus 34-62 × 24$46 \mathrm{~mm}$, semicircular to more or less spathulate, reflecting the pores below (tessellate), pilear surface smooth, weakly zonate, weakly striate, sulcate near base in some specimens, creamy white to yellowish white to pale yellow (4A2-3) when young turning ochraceous with

\begin{tabular}{|c|c|c|c|c|}
\hline \multirow{2}{*}{ Species name } & \multirow{2}{*}{ Voucher no. } & \multicolumn{2}{|c|}{ GenBank accession no. } & \multirow[t]{2}{*}{ Reference } \\
\hline & & ITS & nrLSU & \\
\hline F. roseus & GVM-754 & MT012095 & MT012097 & In this study \\
\hline F. roseus & GVM-787 & MT012371 & MT012370 & In this study \\
\hline F.roseus & MEH-19-15 & MT012096 & MT012099 & In this study \\
\hline F. septatus & Zhou287 & KX548968 & - & Zhou and Cui 2017 \\
\hline F. spatulatus & Cui8290 & KX548969 & - & Zhou and Cui 2017 \\
\hline F. spatulatus & Dai13615A & KU189775 & KU189806 & Zhou and Cui 2017 \\
\hline F. spatulatus & WD1576 & AB587633 & AB587622 & Sotome et al. 2013 \\
\hline F. subtropicus & Cui4292 & KX548970 & - & Zhou and Cui 2017 \\
\hline F. subtropicus & Li1938 & KX548971 & - & Zhou and Cui 2017 \\
\hline F.sp. & MEL2382969 & KP012829 & KP012829 & Zhou and Cui 2017 \\
\hline Neofavolus alveolaris & Dai11290 & KU189768 & KU189799 & Zhou and Cui 2017 \\
\hline N. alveolaris & TUMH 50003 & AB735968 & AB735949 & Sotome et al. 2013 \\
\hline N. alveolaris & TUMH 50004 & AB735967 & AB735948 & Sotome et al. 2013 \\
\hline N. cremeoalbidus & TUMH 50006 & AB735979 & AB735956 & Sotome et al. 2013 \\
\hline N. cremeoalbidus & TUMH 50009 & $A B 735980$ & AB735957 & Sotome et al. 2013 \\
\hline N. mikawae & Cui11152 & KU189773 & KU189804 & Zhou and Cui 2017 \\
\hline N. mikawae & TFM F-27416 & AB735962 & AB735942 & Sotome et al. 2013 \\
\hline N. suavissimus & DSH2011 & KP283496 & KP283525 & Zhou and Cui 2017 \\
\hline N. suavissimus & LE202237 & KM411460 & KM411476 & Zhou and Cui 2017 \\
\hline N.sp. & MA672 & KP283506 & KP283524 & Zhou and Cui 2017 \\
\hline N.sp. & SAV10 & KP283507 & KP283526 & Zhou and Cui 2017 \\
\hline Trametes conchifer & FP 106793sp & JN164924 & - & Zhou and Cui 2017 \\
\hline Ganoderma lingzhi & Dai 12574 & KJ143908 & - & Zhou and Cui 2017 \\
\hline
\end{tabular}

maturity, gradually darkening towards margin. Margin sterile, entire to lobed in some specimens, acute, inrolled when dried, pale orange to light orange (5A3-5) when young, drying brownish orange to dark brown (5F68). Hymenophore poroid, hexagonal/radially elongated, $0.5-7 \times 0.5-3 \mathrm{~mm}$, yellowish white to pale yellow (3A23 ) when young turning pale orange with maturity (5A3). Context to $3 \mathrm{~mm}$ thick in pilear region, gradually widening towards base, homogenous, cream colored. Tubes 1-6 mm long, shallow near margin and base, dissepiments thin, entire to more or less lacerate with maturity, orange to deep orange (5A6-8) when young turning golden yellow (5B7-8) with maturity. Stipe 3-7 × 2-3 $\mathrm{mm}$, lateral, glandular, smooth, concolorous with pilear surface (5A3).

Pileipellis undifferentiated, composed of non-agglutinated dense hyphae. Context composed of loosely interwoven with dominating skeleton-binding hyphae, generative hyphae rare; generative hyphae $1.5-2.0 \mu \mathrm{m}$ wide, rare, clamped, smooth, thin-walled, smooth, hyaline; skeleto-binding hyphae 2-6 $\mu \mathrm{m}$ wide, moderately to thick-walled wall to $2.5 \mu \mathrm{m}$ thick, frequently branched, smooth, hyaline. Trama composed of loosely interwoven with dominating skeleto-binding hyphae, generative hyphae rare; generative hyphae $2-5 \mu \mathrm{m}$ wide, rare, clamped, thin-walled, branched, smooth, hyaline; skeleto-binding hyphae 2-6 $\mu \mathrm{m}$ wide, moderately to thickwalled wall up to $2.5 \mu \mathrm{m}$ thick, frequently branched, smooth, hyaline. Hymenium composed of basidia, basidioles, and cystidioles; cystidioles $11-33 \times 6-12 \mu \mathrm{m}$, infrequent, thin-walled, smooth hyaline. Basidia $23-28 \times$ 7-9 $\mu \mathrm{m}$, clamped at base, thin-walled, smooth hyaline, 


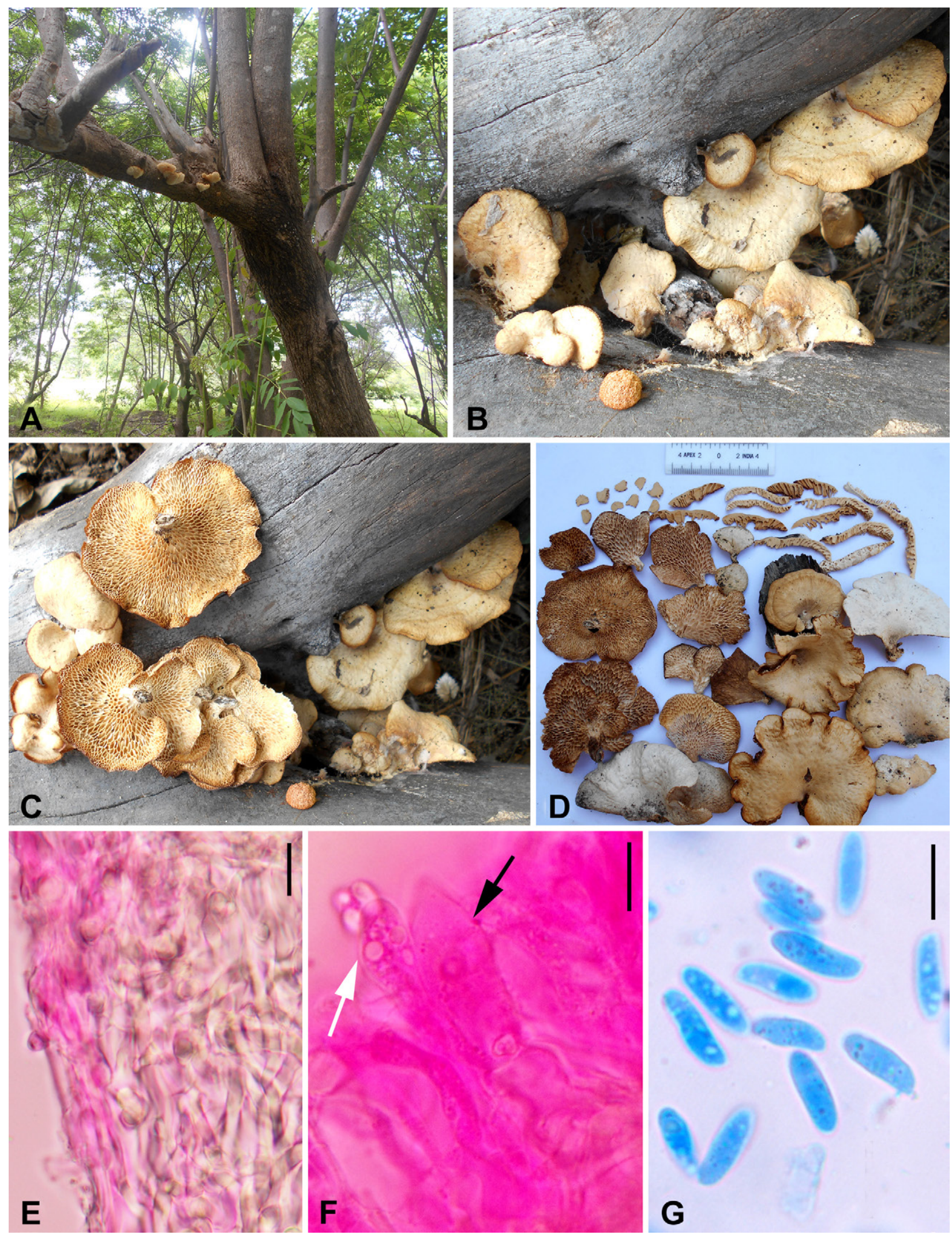

Figure 3. Favolus roseus. A. Habitat. B-D. Habit showing macromorphological features. E. undifferentiated pileipellis composed of nonagglutinated dense hyphae. F. Basidia (white arrow) and cystidioles (black arrow). G. Basidiospores. Scale bars $=10 \mu \mathrm{m}$. 

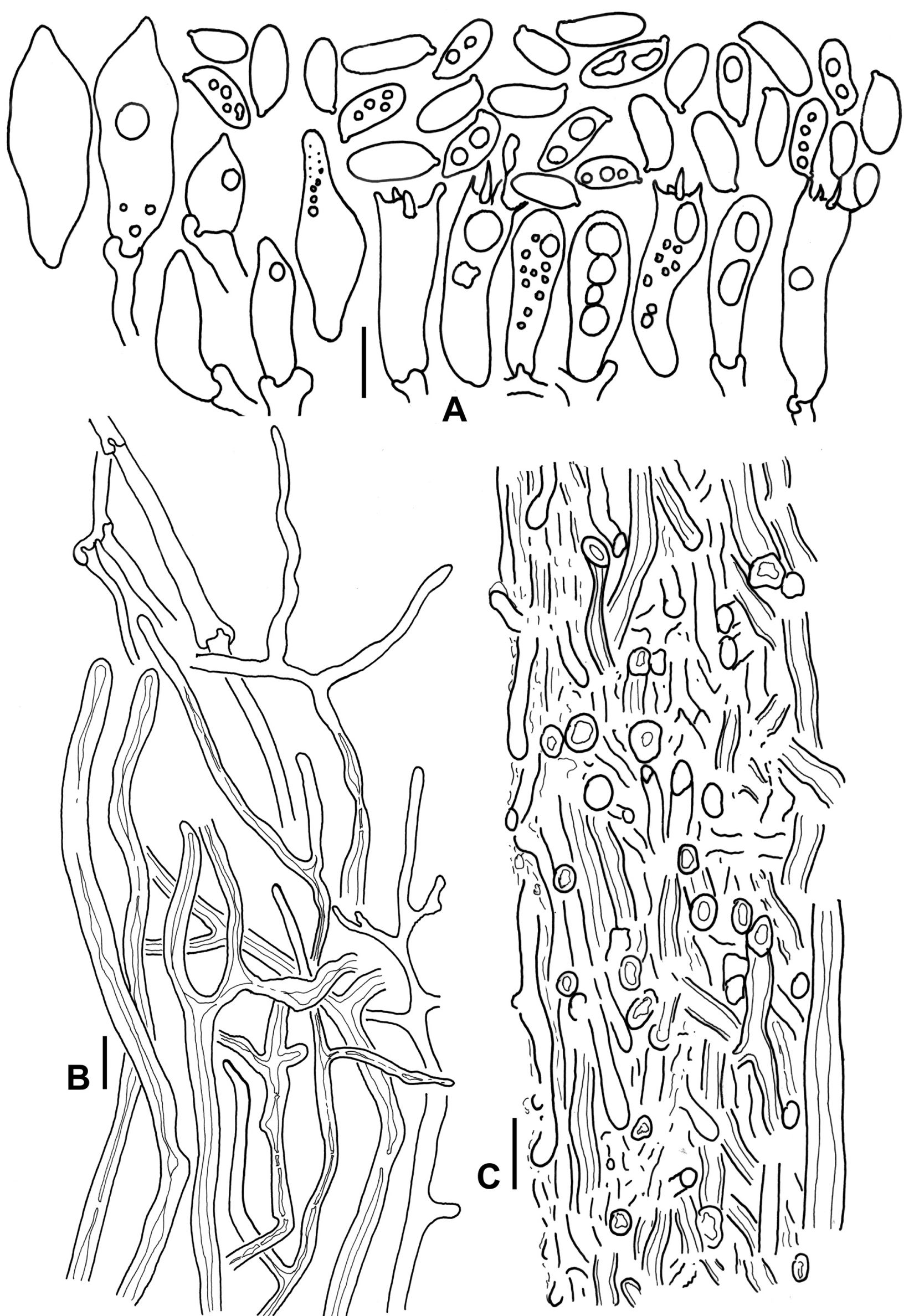

c (c) (c) in:

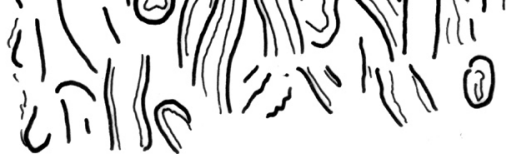

Figure 4. Favolus roseus. A. Basidia, Basidioles, Cystidioles and Basidiospores. B. Generative and skeleto-binding hyphae. C. Drawing showing undifferentiated pileipellis composed of non-agglutinated dense hyphae. Scale bars $=10 \mu \mathrm{m}$. 
4-sterigmate (sterigmata 1.5-4 $\mu \mathrm{m}$ long). Basidiospores 8.0-(11.01)-12.9 × 3.1-(4.13)-5.1 $\mu \mathrm{m}, \mathrm{Q}=2-(2.51)-3.28$ $(n=70)$, cylindrical, thin-walled, smooth, apiculate, hyaline, non-amyloid.

\section{Discussion}

We sampled from large areas of India covering the three large states of Bihar, Jharkhand and Maharashtra in order to record the morphological features and our data were similar to that of Sotome et al. (2013). Until now, wood-decaying polypores in India have seldom been phylogenetically compared with well-known taxa elsewhere in the world, and thus, we phylogenetically compared Indian $F$. roseus with materials from Tanzania, Sri Lanka, Singapore, and Malaysia. Our phylogenetic analysis using combined nrITS and nrLSU genes resolved both Favolus and Neofavolus as separate monophyletic groups with significant support (MLBS $=90 \%$ ). Our multigene phylogenetic results shows that our Indian $F$. roseus (GVM-754, GVM-758 and MEH19-15) are nested within the $F$. roseus clade (Fig. 1, blue arrow) consisting of Sri Lankan, Malaysian, and Tanzanian specimens (UOC WASNP W13, TFM F-20589, and IJ04, respectively) with strong bootstrap support (MLBS $=100 \%$ ). This suggests a strong similarity or conspecificity of Asian and African F. roseus. In addition to our phylogenetic analysis, a comparison of morphological characters of F. roseus and related species in Southeast Asia are presented in Table 2.

The following specific epithets are used for Indian Favolus: F. brasiliensis (Fr.) Fr., F. bengala Bose, F. boucheanus Klotzsch, F. grammocephalus (Berk.) Imazeki, F.jacobaeus Sacc. \& Berl., F. spatulatus (Jungh.) Lév., F. tenerrimus Berk., F. tenuiculus P. Beauv., and F. tessellatus Mont. (Bakshi 1971; Bilgrami et al. 1991; Roy and De 1996; Leelavathy and Ganesh 2000; Mohanan 2011; Sharma 2012). Among these names, F. boucheanus and F. spatulatus are now placed in the genus Polyporus P. Micheli ex Adans. and Royoporus A.B. De, respectively, and $F$.jacobaeus and $F$. tenerrimus are without any clear taxonomic placement (as per Species Fungorum 2021). The taxonomy of $F$. brasiliensis, $F$. tessellates, and $F$. roseus is controversial, as these are treated by some authors as synonyms of F. tenuiculus (Species Fungorum 2021), whereas, F. brasiliensis and F. roseus are cryptic species behind the F. tenuiculus (Sotome et al. 2013). However, the combination of morphological features, such as small basidiomata $(34-62 \times 24-46 \mathrm{~mm})$ with greyish orange to yellowish orange pileus surface (undifferentiated pileipellis composed of non-agglutinated dense hyphae), radially elongated large pores (1.0-4.0 $\times$ $0.5-1.5 \mathrm{~mm})$ and basidiospore size $(8.0-12.9 \times 3.1-5.1$ $\mu \mathrm{m})$, suggest that our material belongs to $F$. roseus, as circumscribed by Sotome et al. (2013).

Favolus grammocephalus is easily morphologically differentiaed from $F$. roseus, including our Indian specimens, due to its small pores (3-5 per mm; Sharma
2012). Favolus brasilensis (basidiospores 9-12 × 2-3 $\mu \mathrm{m}$; Sharma 2012) and F. spatulatus (basidiospores 5-8 $\times 2-3 \mu \mathrm{m}$; De 1996) have a white pilear surface when fresh, coupled with a narrower tube $(2 \mathrm{~mm}$; Sharma 2012), which is in contrast to the yellowish-white to paleyellow pilear surface and wider tubes (to $6 \mathrm{~mm}$ ) in $F$. roseus. But, the name $P$. tenuiculus (although its identity was questioned by Sotome et al. (2013) has been applied several times for specimens having white pileus with short distinct stipe, decurrent hymenophore, presence of gloeoporus hyphae and cystidioles (Roy and De 1996; Leelavathy and Ganesh 2000; Mohanan 2011; Sharma 2012). All of these three taxa are part of F. tenuiculus species complex which look superficially alike, but their pilear surface micromorphology and phylogeny reveals them to be independent taxa, of which $F$. roseus was unknown from Indian mycobiota.

Extralimital species like F. septatus J.L. Zhou \& B.K. Cui is a similar species reported from south China. It has a pinkish-buff to yellowish-brown pileus and yellowishbrown to apricot-orange hymenophore, but its pores are smaller (0.5-1 per $\mathrm{mm})$ and its stipe is short but distinct (Zhou and Cui 2017). The temperate North American Neofavolus americanus J.H. Xing, J.L. Zhou \& B.K. Cui macromorphologically looks similar to F. roeseus but is distinguished by its glabrous pilear surface with pileipellis as a cutis composed of parallel and agglutinated generative hyphae (Sotome et al. 2013). Neofavolus is also restricted to the northern temperate region (Sotome et al. 2013).

Our study partially resolves the taxonomy of the $F$. tenuiculus complex from India using molecular tools. Future phylogenetic studies will likely find additional hidden diversity in the genus Favolus, including in the $F$. tenuiculus species complex.

\section{Acknowledgements}

$\mathrm{MEH}$ is grateful to the Director of the Botanical Survey of India (BSI), Kolkata and $\mathrm{HoO}$, AJC Bose Indian Botanic Garden, BSI, Howrah for providing facilities. AG is grateful to the Department of Botany and Microbiology, H.N.B. Garhwal University, Srinagar, Garhwal for providing facilities.

\section{Authors' Contributions}

Conceptualization: AG, MEH. Data curation: AG, VUG, VPM. Formal analysis: AG, MEH. Investigation: VUG, MEH, VPM. Methodology: VPM. Resources: AG. Writing - original draft: AG, MEH. Writing - review and editing: AVK.

\section{References}

Altschul SF, Madden TL, Schäffer AA, Zhang J, Zhang Z, Miller W, Lipman DJ (1997) Gapped BLAST and PSI-BLAST: a new generation of protein database search programs. Nucleic Acids Research 25: 3389-3402. https://doi.org/10.1093/nar/25.17.3389 


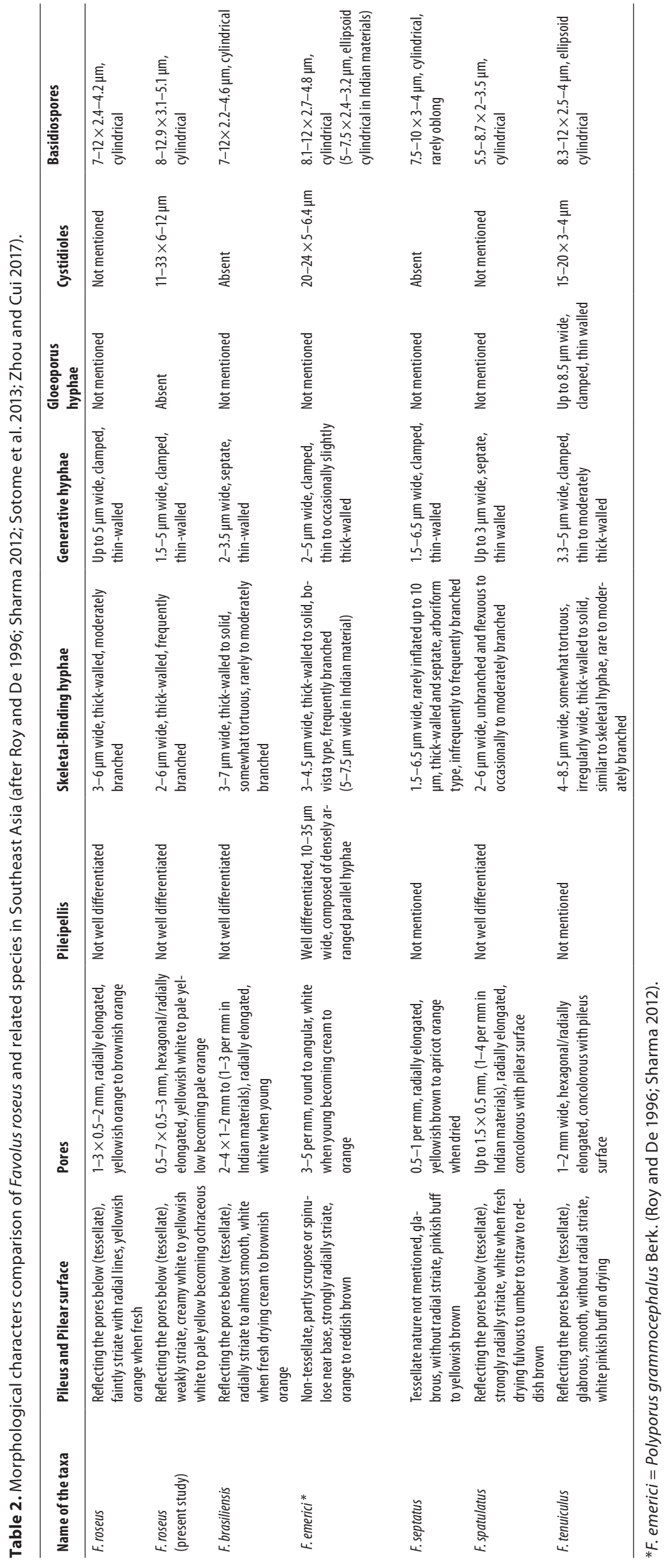


Bakshi BK (1971) Indian Polyporaceae (on trees and timber). I.C.A.R. New Delhi, India, 246 pp.

Bilgrami KS, Jamaluddin S, Rhizwi MA (1991) Fungi of India list and references. Second ed. Today \& Tomorrow's Printers and Publishers, New Delhi, India, 798 pp.

Clark K, Karsch-Mizrachi I, Lipman DJ, Ostell J, Sayers EW (2016) GenBank. Nucleic Acids Research 44: D67-D72. https://doi. org/10.1093/nar/gkv1276

Corner EJH (1984) Ad Polyporaceas II \& III. Beihefte zur Nova Hedwigia 78: 1-222.

Cui B-K, Li H-J, Ji X, Zhou J-L, Song J, Si J, Yang Z-L, Dai Y-C (2019) Species diversity, taxonomy and phylogeny of Polyporaceae (Basidiomycota) in China. Fungal Diversity 97: 137-302. https://doi.org/10.1007/s13225-019-00427-4

De AB (1996) Royoporus-a new genus for Favolus spathulauts. Mycotaxon 60: 143-148.

Drechsler-Santos ER, Ryvarden L, Wartchow F, Cavalcanti MAQ (2008) Polyporuselongoporus (Aphyllophorales, Poriaceae) sp. nov. Synopsis Fungorum 25: 38-43.

Drummond AJ, Ashton B, Buxton S, Cheung M, Cooper A, Heled J, Kearse M, Moir R, Stones Havas S, Sturrock S, Thierer T, Wilson A (2010) Geneious v. 5.1. https://www.geneious.com

Edler D, Klein J, Antonelli A, Silvestro D (2021) raxmlGUI 2.0: a graphical interface and toolkit for phylogenetic analyses using RAxML. Methods in Ecology and Evolution 12: 373-377. https:// doi.org/10.1111/2041-210X.13512

Hall TA (1999) BioEdit: a user-friendly biological sequence alignment editor and analysis program for Windows 95/98/NT. Nucleic Acids Symposium Series 41: 95-98.

Juma I, Mshandete AM, Tibuhwa DD, Kivaisi AK (2016) Identification of Tanzaniansaprophytic edible mushrooms by amplification and sequencing of ITS/LSU regions of ribosomal RNA operon. Tanzania Journal of Science 42: 109-121.

Katoh K, Rozewicki R, Yamada KD (2019) MAFFT online service: multiple sequence alignment, interactive sequence choice and visualization. Briefings in Bioinformatics 20 (4): 1160-1166. https:// doi.org/10.1093/bib/bbx108

Kornerup A, Wanscher JH (1978) Methuen handbook of colour. Third edition. Eyre, London, UK, 252 pp.

Kumar S, Stecher G, Tamura K (2016) MEGA7: Molecular Evolutionary Genetics Analysis version 7.0 for bigger datasets. Molecular Biology and Evolution 33 (7): 1870-1874. https://doi.org/10.1093/ molbev/msw054

Leelavathy KM, Ganesh PN (2000) Polypores of Kerala. Daya Publishing House, Delhi, India, 165 pp.

Lloyd CG (1922) Mycological notes 67. Mycological writings 7 (67): $1137-1168$.
Mohanan C (2011) Macrofungi of Kerala. KFRI Handbook No. 27. Kerala Forest Research Institute, Peechi, Kerala, India, 597 pp.

Núñez M, Ryvarden L (1995) Polyporus (Basidiomycotina) and related genera. Synopsis Fungorum 10: 1-85.

Núñez M, Ryvarden L (2001) East Asian polypores. Vol. 2. Synopsis Fungorum 14: 1-522.

Palacio M, Santos ERD, Menolli N, Silveira RMB (2021) An overview of Favolus from the Neotropics, including four new species. Mycologia. https://doi.org/10.1080/00275514.2021.1878797

Papp V, Dima B (2017) Favolus gracilisporus (Polyporaceae, Basidiomycota), an East Asian polypore species new to the European mycobiota. Mycosphere 8 (6): 1177-1184. https://doi.org/10.5943/ mycosphere $/ 8 / 6 / 7$

Roy A, De AB (1996) Polyporaceae of India. International Book Distributors, Dehradun, India, $309 \mathrm{pp}$.

Ryvarden L (1991) Genera of polypores, nomenclature and taxonomy Synopsis Fungorum 5: 1-363.

Ryvarden L, Iturriaga T (2004) Studies in Neotropical polypores 21. New and interesting species from Venezuela. Synopsis Fungorum 18: $68-75$.

Sharma JR (2012) Aphyllophorales of Himalaya. Botanical Survey of India, Kolkata, India, 590 pp.

Silveira RMB, Wright JE (2005) The taxonomy of Echinochaete and Polyporus s. str. in South America. Mycotaxon 93: 1-59.

Sotome K, Akagi Y, Lee SS, Ishikawa, Hattori T (2013) Taxonomic study of Favolus and Neofavolus gen. nov. segregated from Polyporus (Basidiomycota, Polyporales). Fungal Diversity 58: 245 266. https://doi.org/10.1007/s13225-012-0213-6

Species Fungorum (2021) http://www.speciesfungorum.org. Accessed on: 2021-6-17.

Vilgalys R, Hester M (1990) Rapid genetic identification and mapping of enzymatically amplified ribosomal DNA from several species of Cryptococcus. Journal of Bacteriology 172: 4238-4246. https:// doi.org/10.1128/jb.172.8.

White TJ, Bruns T, Lee SS, Taylor J (1990) Amplification and direct sequencing of fungal ribosomal RNA genes for phylogenetics. In: Innis MA, Gelfand DH, Sninsky JJ, White TJ (Eds.) PCR protocols: a guide to methods and applications. Academic Press, New York, USA, 315-322. https://doi.org/10.1016/B978-0-12-3721808.50042-1

Xing J-H, Zhao J-L, Cui B-K (2020) Two new species of Neofavolus (Polyporales, Basidiomycota) based on morphological characters and molecular evidence. Mycological Progress 19: 471-480. https://doi.org/10.1007/s11557-020-01574-8

Zhou J-L, Cui B-K (2017) Phylogeny and taxonomy of Favolus (Basidiomycota). Mycologia 109 (5): 766-779. https://doi.org/10.1080 /00275514.2017.1409023 